\title{
Radiological studies on endangered Mascarene fauna
}

\author{
J. E. Cooper and C. D. West
}

\begin{abstract}
When managing small populations of endangered species, in the wild and in captivity, the premature death of even one individual may give cause for concern. The authors carried out whole-body radiographs (X-rays) on dead specimens of endangered Mascarene fauna-three species of birds, three species of reptiles and one bat species. They found skeletal problems indicating traumatic injuries and nutritional abnormalities. The authors suggest that the technique has a role to play in the investigation of deaths in populations of endangered species, and may provide information that leads to improved management of the species in question.
\end{abstract}

Many vertebrate species native to Mauritius and adjacent Round Island in the Indian Ocean, are on the verge of extinction in the wild and are rare in captivity. There are many reasons for the decline in free-living populations, the main ones being habitat destruction, the introduction of alien competitors and predatory species, and the increased susceptibility of small populations to natural disasters such as cyclones and, possibly, to diseases and parasites. In recent years the Mauritius Government, in collaboration with the Jersey Wildlife Preservation Trust (JWPT), has set up captive breeding populations of a number of threatened Mascarene species both in Mauritius and on Jersey (Durrell and Durrell, 1980).

Research into behavioural, nutritional and reproductive aspects of the husbandry of the species kept in captivity has proved fruitful and yielded a considerable amount of valuable data. An animal health programme has long been a feature of the Mauritius project (Cooper et al., 1981) and this has permitted the pathological examination of the majority of specimens that have died in Jersey and, in a few cases, of wild casualties collected in Mauritius. An integral part of the animal health monitoring is the X-ray examination of carcasses (whole-body radiography). This provides a 'window' into the internal anatomy of the animal, 18 particularly skeletal structures, and is a technique that has seldom been used as part of a postmortem examination of endangered species in the past.

In this paper we report and analyse radiographical findings in the Round Island gecko Phelsuma guentheri, Round Island skink Leiolopisma telfaini, keel-scaled boa Casarea dussumieri, Mauritius kestrel Falco punctatus, pink pigeon Nesoenas mayeri, Rodrigues fody Foudia flavicans and Rodrigues fruit bat Pteropus rodricensis, submitted from Mauritius or Jersey.

Formalin-fixed carcasses were received either direct from the Conservation Project on Mauritius or from JWPT. They were imported under the authority of a CITES licence under the Endangered Species (Import and Export) Act 1976 from the Department of the Environment. On arrival at the Royal College of Surgeons the carcasses were subjected to a standard procedure, which involved entering the details of the case in a day-book, careful external examination, whole body radiography, a full post-mortem examination, and subsequent laboratory tests. The carcasses remain the property of the Mauritius Government and are stored in the Mascarene Collection at the Royal College of Surgeons (Registry of Comparative Pathology, 1981; Cooper and Jones, 1986).

Oryx Vol 22 No 1, January 1988 
As a general rule, specimens were positioned ventro-dorsally; however, in some cases, additional lateral views were also taken. The machine used was a dental design X-ray machine (Newton-Victor Ltd, London, UK), sited in a purpose-built lead cabinet with a safety door. Two types of film were routinely employedKodak Direct Exposure film and Kodak Graphic Arts film (Gravure positive). Settings for both types of film were $40 \mathrm{kv}$ and $3 \mathrm{~mA}$, and exposure times ranged from 0.5 seconds for the Direct Exposure and 30-60 seconds for the Gravure Positive. Standard processing procedures were followed.

For each species the specimens were divided according to whether they were mature or immature. This division was made on the basis of historical information, size of specimen and the degree of apparent ossification, particularly at the ends of the long bones. In the geckos and skinks, stores of calcium (for bone mineralization, and possible future egg-laying in female geckos) in the neck region were more obvious in younger specimens.

Radiological abnormalities were classified as to their likely causes. Any specimens showing more than one category of damage were listed under each appropriate heading.

\section{Findings and discussion}

The radiological interpretations are given in Table 1 and analysed in more detail below.

Despite its age (manufactured in 1959) and simple design, the X-ray machine produced radiographs of very good quality (Figure 1).

Formalin-fixed specimens proved suitable for wholebody radiography, but in some cases were difficult to position satisfactorily on the X-ray plate because of distortion. As a result a small number could not be interpreted properly. Soaking in warm water made some of the carcasses more pliable and this also reduced the risk of unintentional damage during handling.

Research workers who preserve specimens for subsequent radiological examination should ensure that they are carefully positioned in the fixative; this may be facilitated by pinning them to a piece of cork or plastic.

\section{Round Island gecko}

Out of 11 specimens, X-rays of five had obvious abnormalities (radiological lesions) of the skeleton. Poor mineralization of the foremost parts of both upper and lower jaws ('soft jaw') was present in all five and multiple 'kinking' (scoliosis)

Table 1. Interpretation of whole-body radiographs of some Mascarene species

\begin{tabular}{|c|c|c|c|c|c|c|c|}
\hline Species & $\begin{array}{l}\text { No. } \\
\text { examined }\end{array}$ & Age & $\begin{array}{l}\text { No abnormalities } \\
\text { detected (NAD) }\end{array}$ & Trauma & $\begin{array}{l}\text { Nutritional/ } \\
\text { Developmental }\end{array}$ & Infection & $\begin{array}{l}\text { No interpretation } \\
\text { possible }\end{array}$ \\
\hline \multirow{2}{*}{$\begin{array}{l}\text { Round Island } \\
\text { gecko Phelsuma } \\
\text { guentheri }\end{array}$} & 7 & Immature & 4 & - & 3 & - & - \\
\hline & 4 & Mature & 2 & - & 2 & - & - \\
\hline \multirow{2}{*}{$\begin{array}{l}\text { Round Island skink } \\
\text { Leiolopisma telfairii }\end{array}$} & $39\}_{120}$ & Immature & 6 & 4 & 27 & - & 2 \\
\hline & $81\}$ & Mature & 36 & 6 & 36 & 3 & - \\
\hline \multirow{2}{*}{$\begin{array}{l}\text { Round Island boa } \\
\text { Casarea dussumieri }\end{array}$} & $6\}$ & Immature & 6 & - & - & - & - \\
\hline & 1. & Mature & 1 & - & - & - & - \\
\hline \multirow{2}{*}{$\begin{array}{l}\text { Mauritius kestrel } \\
\text { Falco punctatus }\end{array}$} & $1)$ & Immature & - & - & 1 & - & - \\
\hline & 8 & Mature & 8 & - & - & - & - \\
\hline \multirow{2}{*}{$\begin{array}{l}\text { Pink pigeon } \\
\text { Nesoenas mayeri }\end{array}$} & $18\}$ & Immature & 7 & 2 & - & - & 9 \\
\hline & $13\}$ & Mature & 10 & - & - & 1 & 2 \\
\hline \multirow{2}{*}{$\begin{array}{l}\text { Rodrigues fody } \\
\text { Foudia flavicans }\end{array}$} & $7\}$ & Immature & 4 & 1 & 1 & - & 1 \\
\hline & $17\}^{24}$ & Mature & 15 & 1 & 1 & - & - \\
\hline \multirow{2}{*}{$\begin{array}{l}\text { Rodrigues truit bat } \\
\text { Pteropus rodricensis }\end{array}$} & $25\}$ & Immature & 12 & 12 & 1 & - & - \\
\hline & $15\}^{40}$ & Mature & 11 & 4 & - & - & - \\
\hline
\end{tabular}




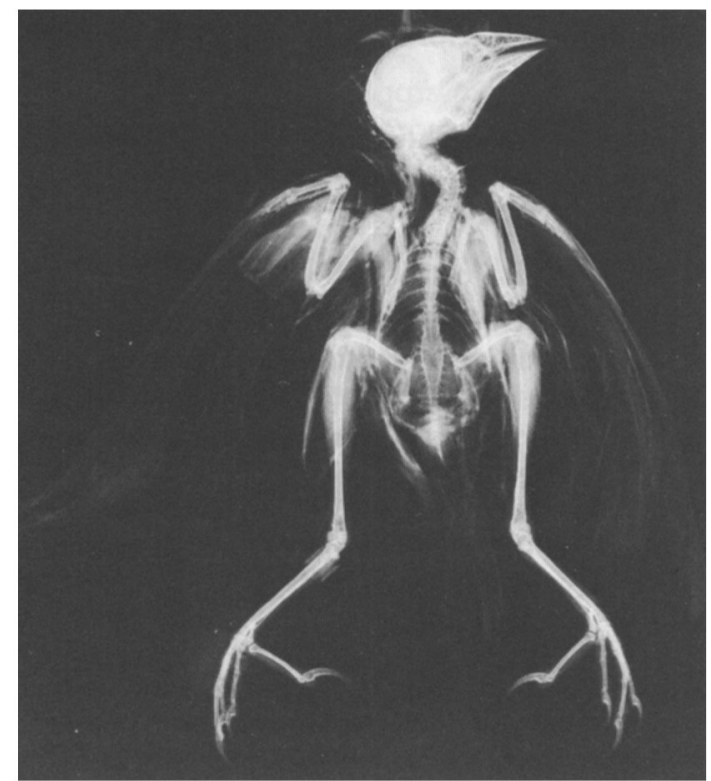

Figure 1. Ventro-dorsal view of Rodrigues fody.

This specimen has no visible radiographic abnormalities, but it is included to show the quality of the radiographs that can easily be attained with the correct film type on a relatively unsophisticated X-ray machine.

was evident in tail vertebrae of the three immature specimens. Calcium stores were still present, suggesting that demineralization or poor mineralization can occur without depletion of these stores, or that the condition may have arisen at an earlier stage.

\section{Round Island skink}

Of the radiological lesions noted, the majority had a nutritional/developmental cause. The three specimens with infections had skin wounds with underlying gas shadows - either air or following the action of gas-producing organisms. Lesions due to physical injury in younger animals were mainly of the digits, with a greater prevalence of missing digits on the forelimb. Older specimens, apart from one with a healed femoral fracture, were missing the tips of their tails, and in all cases some degree of regeneration could be seen.

In so far as problems attributed to developmental or nutritional causes are concerned (Figures 2 and 3), there was much variation in the severity of the lesions, although they followed a similar pattern in both immature and mature specimens. 20
The most prevalent skeletal abnormality was lateral kinking, or scoliosis, in the mildest cases involving only the distal tail vertebrae, with the next most frequent sites being at the level of the pelvic and pectoral girdles. Specimens exhibiting thoracic scoliosis invariably also had some degree of rib distortion. In more severe cases, abnormal mineralization (osteodystrophy) of long bones occurred.

There was reduced bone density apparent on X-rays - but increased density of soft tissues surrounding bone. These soft tissues were also often

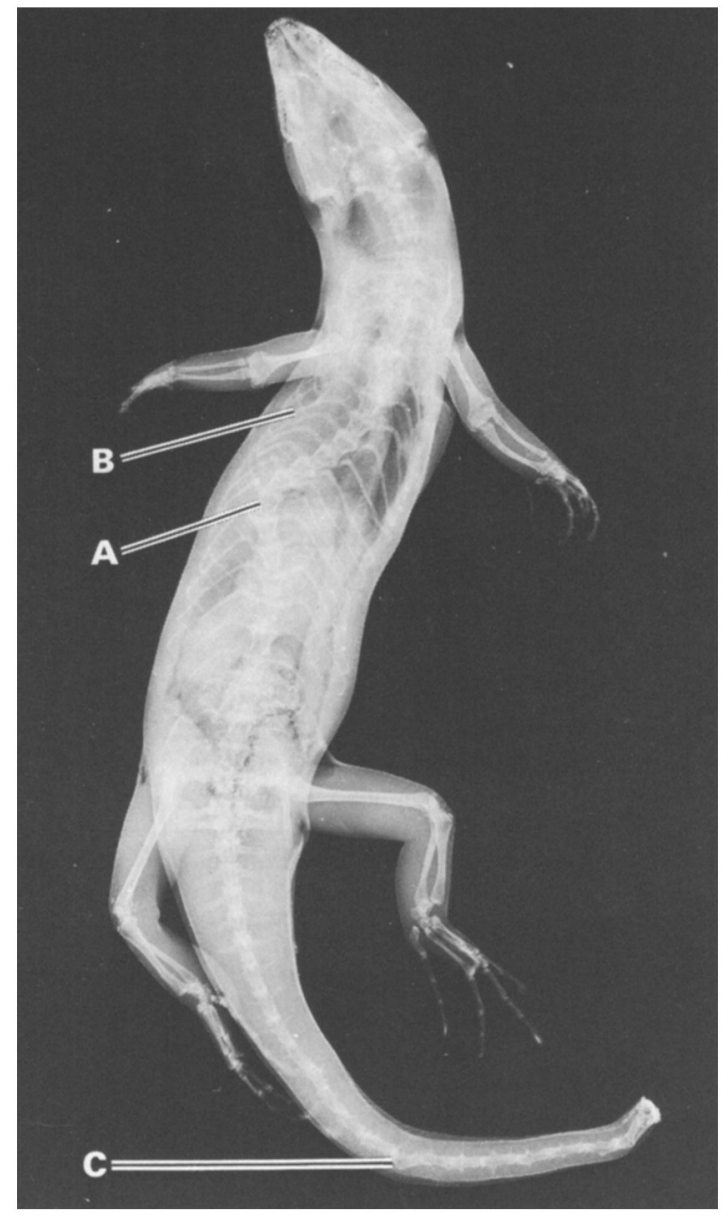

Figure 2. Dorso-ventral view of mature Round Island skink. Lateral deviation of thoracic vertebrae (A) and rib distortion (B) are clearly visible and the distal coccygeal vertebrae (C) are variably demineralized and distorted. The tip of the tail has been lost. The long bones and skull bones are well formed and mineralized.

Oryx Vol 22 No 1, January 1988 
swollen. The diameter of the shaft of long bones was increased and distortion of the growth plates at each end marked.

Developmental abnormalities in Round Island skinks have been reported previously by Cooper et al. (1982) who suggested that genetic factors might be responsible. Subsequent work by Tonge (1985) showed that the incidence of abnormalities could be markedly reduced, or even eliminated, if the animals were exposed to ultraviolet light. Whatever the cause, this problem is clearly one that would have a marked effect on the ability of the skink to survive in the wild.

Only a very small number of younger specimens (approximately 5 per cent) showed severe signs of osteodystrophy, which might have led to reduced mobility during life.

\section{Round Island boa}

No abnormalities could be detected in any of the specimens submitted. An interesting case was a free-living snake, found dead on Round Island, which on radiographical examination was seen to have swallowed a Round Island gecko (Figure 4). Both predator and prey appeared normal radiographically.

\section{Mauritius kestrel}

The one immature specimen had bowing of the long bones, which was attributed to a nutritional problem. Although a number of other diseases have been recorded in this species (Cooper et al., 1981) this was the first time that any skeletal change was diagnosed or suspected, and illustrates the value of routine radiography. An additional finding, although not pathological, was the similarity of the skeleton of this species - a falcon adapted to an arboreal existence - to that of an accipiter-(a short-winged hawk) such as a sparrowhawk.

\section{Pink pigeon}

Positioning specimens of this species presented problems, particularly in the case of the chicks (squabs), radiographs of which proved difficult to interpret as the degree of ossification was small. Trauma in both cases was due to downward Endangered Mascarene fauna pressure (squashing); in one chick both tibiae were fractured, in the other, damage was generalized and severe. This can probably be attributed to parental accidents.

\section{Rodrigues fody}

No interpretation was possible in the case of the new-born chick because of poor positioning. In the two birds showing signs of trauma there

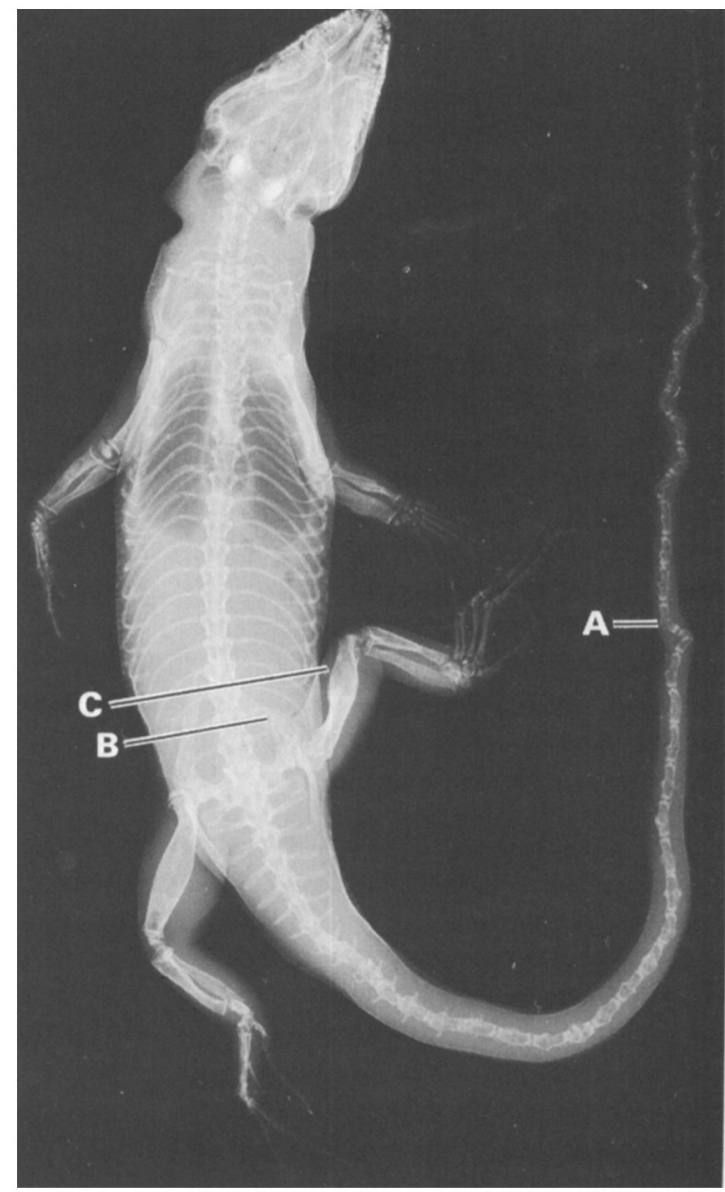

Figure 3. Dorso-ventral view of mature Round Island skink. This specimen shows marked skeletal abnormalities. The backbone is less obviously affected apart from scoliosis ('kinking') of coccygeal vertebrae (A), but closer examination shows poor mineralization of vertebrae and limb girdles with distortion $(\mathrm{B})$, particularly of the pelvis. Long bones are severely abnormally mineralized, with reduced density of the bone coupled with an increase in shaft diameter and pronounced distortion of growth plates (epiphyses) (C). Calcified areas in the neck are well defined. 
appeared to be evidence of underlying, predisposing, metabolic problems, with variable density of the long bones and 'bowing', especially of the long leg bones in the immature fody, and the wing bones in the mature specimen. There were pathological fractures of both tibiae in the chick, and deviation and a band of new bone denoting an old trauma, mid-shaft, humeral fracture in the adult. One other chick had 'turned-in' feet, but this was probably due to a positioning artefact. The detection of radiographical abnormalities in one of the first fodies to be hatched at JWPT prompted the introduction of a better balanced diet (Darby et al., 1984) and following this the survival rate increased substantially.

\section{Rodrigues fruit bat}

By far the most significant cause of radiological lesions in this species was trauma. Immature specimens had a preponderance of cranial injuries such as dislocation of the mandibular symphysis (the joint between both lower jaw bones) (Figure 5) and depression fractures of the frontal and temporal bones. Damage to young bats by adults is well recognized. Mature specimens had injuries to the long bones of the leg, especially the femur. Many such injuries were old and had healed well.

\section{Conclusions}

This survey provides hitherto unpublished data on the radiographical anatomy of some of the world's most endangered animals. The results illustrate that routine radiography of carcasses can yield valuable information. Even if a specimen cannot be examined pathologically-for example, because it is required for museum purposes-a whole-body radiograph may some-

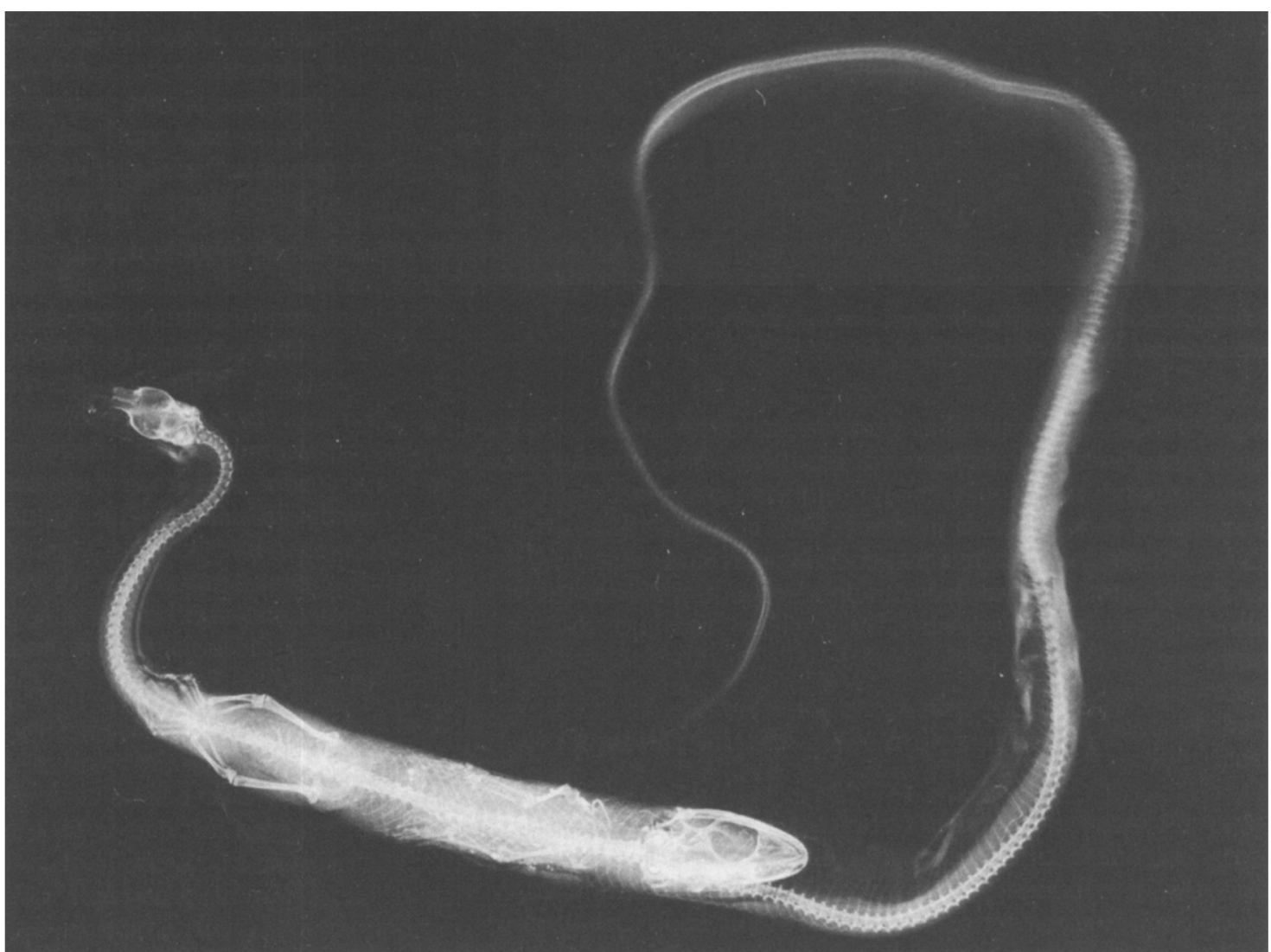

Figure 4. Whole-body view of Round Island boa containing Round Island gecko.

Oryx Vol 22 No 1, January 1988 


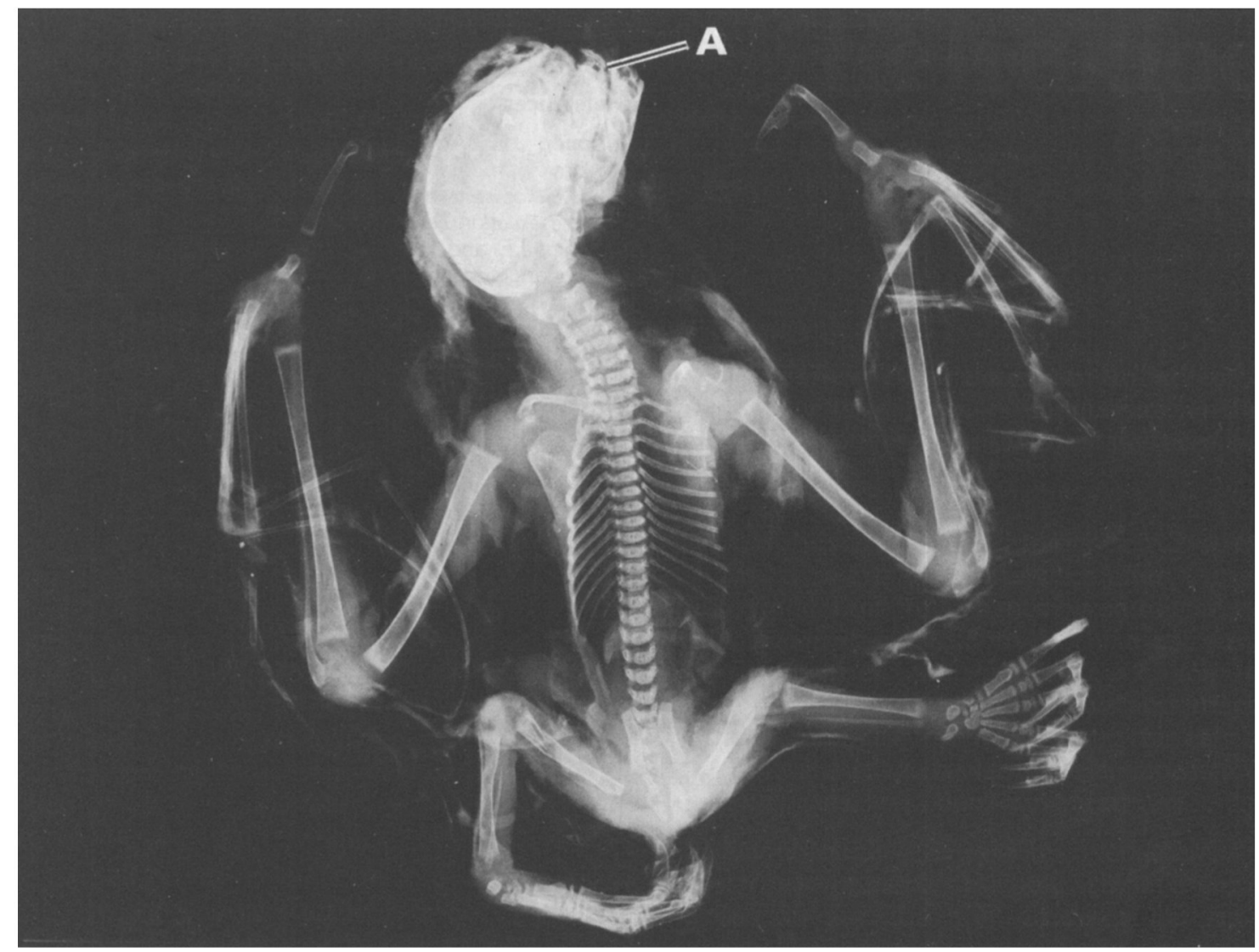

Figure 5. Ventro-dorsal view of Rodrigues fruit bat (lateral view of the head). Immature specimen with a dislocation fracture of the mandibular symphysis (A).

times permit a provisional diagnosis to be made, and will often provide information that is relevant to the management of the species in question. In some cases it may reveal minor changes, e.g. bowing of limbs and healed fractures, which are not immediately apparent at post-mortem examination, but which are of considerable significance.

An expensive $\mathrm{X}$-ray machine is not required so long as the correct film type and exposures are used.

No attempt was made in this survey to correlate radiological findings with data obtained at postmortem examination or during the course of laboratory investigations. This was intentional, since the aim was to ascertain whether radiography alone had a role to play in the investiEndangered Mascarene fauna gation of the deaths of endangered species. Its value in this context is clear. Nor was a distinction drawn between captive and free-living animals, or between those from Mauritius and those from JWPT. Again this was intentional to avoid any bias when reading the radiographs. Nevertheless, under normal circumstances it is clearly wise to combine radiological interpretation with gross examination of the carcass, since the latter may yield additional information or help to explain changes that are seen on X-ray plates.

As increasing numbers of species become threatened, the need to monitor their health status becomes greater. There is evidence that, when a population becomes small, both infectious and non-infectious diseases may assume more importance, because of reduced genetic 
variation-inbreeding (Cooper et al., 1981). Routine post-mortem investigation of captive populations is essential and every effort should be made to extend this to any specimens (generally only few in number) that are found dead, or have to be killed, in the wild. Ideally such material should be subjected to full pathological examination with a wide range of supporting tests. In addition, tissues or carcasses should be subjected to toxicological investigation and material stored for subsequent analysis or culture. Often, however, it is impracticable or impossible to perform all these procedures, especially if finances are limited, or carcasses are requird for museum display or morphological studies. Radiography is a non-invasive procedure, which can be carried out easily and quickly and which is not unduly expensive. It has an important role to play as an adjunct to routine post-mortem examination, but is clearly a valuable tool per se in the investigation of endangered species.

\section{Acknowledgments}

We are grateful to those who submitted material for this study, especially Mr Carl Jones, Miss Julia Tagg and other personnel (present and past) on Mauritius and at JWPT. The support and help of Mr Wahab Owadally, Mr John Hartley and $\mathrm{Mr}$ Jeremy Mallinson are gratefully acknowledged. All the specimens examined are now deposited in the Mascarene Collection at the Royal College of Surgeons in England. Assistance with the examination and cataloguing of specimens was provided by Mr Alan Graham and Mr Ken Applebee. We are indebted to $\mathrm{Mr}$ Carl Hobbs and his colleagues in the Department of Dental Science, Royal College of Surgeons, for assistance with radiography. This manuscript was kindly read and commented upon by Mr Malcolm Brearley and $\mathrm{Dr}$ Richard Wootton.

\section{References}

Cooper, J.E., Arnold, L. and Henderson, G.M. 1982. A developmental abnormality in the Round Island skink (Leiolopisma telfairii). Dodo, Joumal of the Jersey Wildife Preservation Trust, 19, 78-81.

Cooper, J.E. and Jones, C.G. 1986. A reference collection of endangered Mascarene specimens. The Linnean, 2, $32-37$.

Cooper, J.E., Jones, C.G. and Owadally, W. 1981. Morbidity and mortality in the Mauritius kestrel (Falco punctatus). In: Recent Advances in the Study of Raptor Diseases (Eds J.E. Cooper and A.G. Greenwood). Chiron Publications, Keighley.

Darby, P.W.H., Jeggo, D.F. and Redshaw, M.E. 1984. Breeding and management of the Rodrigues fody, Foudia flavicans. Dodo, Journal of the Jersey Wildlife Preservation Trust, 21, 109-126.

Durrell, G. and Durrell, L.M. 1980. Breeding Mascarene wildlife in captivity. Intemational Zoo Yearbook, 20, 112-119.

Registry of Comparative Pathology. 1981. DirectoryResources of Biomedical and Zoological Specimens. Armed Forces Institute of Pathology, Washington D.C.

Tonge, S. 1985. The management of juvenile Telfair's skinks Leiolopisma telfairii with particular reference to the role of ultraviolet light. In: Reptiles: Breeding, Behaviour and Veterinary Aspects. (Eds S. Townson and K. Lawrence). British Herpetological Society, London.

J.E. Cooper, Department of Pathology, Royal College of Surgeons of England, 35-43 Lincoln's Inn Fields, London WC2A 3PN, UK.

C.D. West, * Division of Comparative Medicine, Clinical Research Centre, Watford Road, Harrow, Middlesex HA1 3UJ, UK.

*Present address: ICI Pharmaceuticals Division, Alderley Park, Macclesfield, Cheshire SK10 4TF, UK. 